\title{
PRODUTIVIDADE E CUSTOS DO FELLER-BUNCHER E PROCESSADOR FLORESTAL EM POVOAMENTO DE EUCALIPTO DE PRIMEIRO CORTE ${ }^{1}$
}

\author{
PRODUCTIVITY AND COSTS OF FELLER-BUNCHER AND FOREST PROCESSOR IN STANDS \\ OF EUCALYPTS IN FIRST CUT
}

\author{
Danilo Simões ${ }^{2}$ Paulo Torres Fenner ${ }^{3}$ Maura Seiko Tsutsui Esperancini ${ }^{4}$
}

\begin{abstract}
RESUMO
A racionalização da colheita florestal e a minimização dos custos é uma busca constante por parte dos gestores envolvidos nesse processo, competindo a esses deliberar práticas economicamente viáveis para otimizar essa operação. O objetivo deste estudo foi avaliar técnica e economicamente a produtividade do feller-buncher e do processador florestal em povoamento de eucalipto em primeiro corte. A análise técnica englobou um estudo de tempos e movimentos, produtividade, eficiência operacional e disponibilidade mecânica. A análise econômica englobou os parâmetros do custo operacional, custo de colheita florestal e rendimento energético. Visando à otimização do custo de colheita florestal, o sistema composto pelo feller-buncher e processador florestal apresenta-se como uma alternativa viável tecnicamente e economicamente para a colheita em povoamentos de eucalipto de primeiro corte ou para povoamentos que não possuam árvores bifurcadas.
\end{abstract}

Palavras-chave: colheita de madeira; otimização do processo; tempos e movimentos.

\begin{abstract}
The rationalization of forest harvesting and minimization costs is a constant search by the managers involved in this process, making them decide practices which are economically viable to optimize that operation. This study aimed to evaluate technically and economically the performance of feller-buncher and the forest processor in stands of eucalypts in first cut. The technique analysis included time and movements, productivity, efficiency operational and mechanical availability. The economic analysis included the parameters operational cost, harvesting cost and energy consumption. Aiming the optimization the cost of forest harvesting, the system composed by feller-buncher and processor forest presented itself as a technically and economically viable alternative to harvesting eucalypt in first cut or stands that do not have bifurcated trees.
\end{abstract}

Keywords: forest harvest; process optimization; time and movements.

1 Parte da dissertação de mestrado do primeiro autor.

2 Administrador de Empresas, Dr., Pós-Doutorando em Ciência Florestal, Departamento de Ciência Florestal, Universidade Estadual Paulista "Júlio de Mesquista Filho", Caixa Postal 237, CEP 18610-307, Botucatu (SP) Brasil.simoesdanilo@yahoo.com.br

3 Engenheiro Florestal, Dr., Professor Adjunto do Departamento de Ciência Florestal, Universidade Estadual Paulista "Júlio de Mesquista Filho", Caixa Postal 237, CEP 18610-307, Botucatu (SP), Brasil. fenner@fca.unesp.br

4 Engenheira Agrônoma, Dra ., Professora Adjunta do Departamento de Economia, Sociologia e Tecnologia, Universidade Estadual Paulista "Júlio de Mesquista Filho", Caixa Postal 237, CEP 18610-307, Botucatu (SP), Brasil.maura@fca.unesp.br

Recebido para publicação em 2/05/2011 e aceito em 16/04/2013

Ci. Fl., v. 24, n. 3, jul.-set., 2014 


\section{INTRODUÇÃO}

Inserida em um contexto global que afeta sobremaneira a rentabilidade das empresas, a mecanização da atividade de colheita florestal passa por momentos de grandes inovações e avanços tecnológicos. Entretanto, o setor ainda carece da falta de dados confiáveis para a escolha do sistema e da máquina mais adequada, tanto economicamente, quanto tecnicamente (NASCIMENTO et al., 2011).

Nos últimos anos a intensificação da mecanização da colheita florestal, desencadeou um processo contínuo de avaliação dos rendimentos operacionais e de estimativa dos custos, haja vista que essa etapa despende de elevado percentual dos custos de produção de florestas comerciais (SIMÕES et al., 2010).

Diante disso, a maior parte das empresas florestais que possuem plantios em áreas com declividades não acentuadas, buscam por implementos empregados na colheita $\mathrm{e}$ processamento da madeira que possam oferecer uma melhor produtividade, associada ao menor custo.

Malinovski e Malinovski (1998) relatam que os implementos comumente utilizados no Brasil para as atividades de corte, desgalhamento e traçamento, tanto para a colheita de Pinus spp. como de Eucalyptus spp., são: o cabeçote de harvester, cabeçotes de feller-buncher (sabre, disco e faca), slingshot, delimbers, grades, slashers e garras traçadoras ou processadores.

A produtividade do feller-buncher é descrita por Valverde et al. (1996), os quais relatam que o volume de madeira por hectare é a principal variável de influência na operação de corte de árvores com esse implemento, fato esse confirmado por Fernandes et al. (2009) em avaliação de um sistema de colheita florestal de árvores inteiras.
Em relação ao processador Tarnowski et al. (1999) verificaram em um povoamento de Eucalyptus grandis Hill ex Maiden que o custo de produção do processador diminui em forma exponencial com o aumento do diâmetro das árvores. Lopes et al. (2008) complementam que, a produtividade, custos de produção e rendimento energético da garra traçadora, são influenciados diretamente pela produtividade do povoamento florestal.

Diante do exposto, objetivou-se avaliar técnica e economicamente a colheita e o processamento da madeira com o uso do fellerbuncher e processador florestal em uma floresta de eucalipto de primeiro corte, com vistas a demonstrar a possibilidade de redução dos custos de colheita para essas condições.

\section{MATERIAL E MÉTODOS}

\section{Área experimental}

O estudo foi desenvolvido numa floresta de Eucalyptus grandis Hill ex Maiden de primeiro corte, sem árvores bifurcadas, num talhão homogêneo, equiâneo e seminal, com 72 meses de idade. O plantio foi realizado num espaçamento de $3 \times 2$ metros. A área experimental está localizada nas coordenadas geográficas UTM Zona 22K 754810 E e 7432734 S, no Estado de São Paulo, Brasil, com altitude média de 650 metros acima do nível do mar. O tipo de solo é classificado como AQ1 - Areia Quartzo sálica, a moderado com relevo plano. Segundo a classificação de Wilhelm Köppen, a área do povoamento florestal, está localizada em área de clima Cwa, clima temperado quente (mesotérmico), com chuvas no verão e seca no inverno. O total de precipitação pluvial anual apresenta a média de $1.524,5 \mathrm{~mm}$, com total médio no mês mais seco

TABELA 1: Características dendrométricas das parcelas experimentais.

TABLE 1: Dendrometric characteristics of experimental section.

\begin{tabular}{cccccc}
\hline $\begin{array}{c}\text { Parcelas } \\
\text { experimentais }\end{array}$ & $\begin{array}{c}\text { Área das } \\
\text { parcelas (ha) }\end{array}$ & $\begin{array}{c}\text { Quantidade de } \\
\text { árvores }(\mathrm{n})\end{array}$ & $\begin{array}{c}\text { DAP médio } \\
(\mathrm{cm})\end{array}$ & Altura média $(\mathrm{m})$ & $\begin{array}{c}\text { Volume } \\
\left(\mathrm{m}^{3} \mathrm{cc} \text { árvore }\right)\end{array}$ \\
\hline 1 & 0,74 & 960 & 13,86 & 17,78 & 0,2190 \\
2 & 0,75 & 968 & 14,19 & 18,01 & 0,2226 \\
3 & 0,71 & 879 & 14,30 & 18,15 & 0,2336 \\
4 & 0,77 & 973 & 13,80 & 17,88 & 0,2215 \\
5 & 0,72 & 894 & 12,70 & 17,14 & 0,2310 \\
\hline
\end{tabular}


de $37,4 \mathrm{~mm}$ e $256,7 \mathrm{~mm}$ no mês mais chuvoso (CUNHA et al., 1999).

A área experimental foi subdivida em 5 parcelas (Tabela 1) fixando-se os principais fatores que interferem na produtividade da colheita florestal, ou seja, estudou-se a colheita sob condições homogêneas de povoamento, solo, relevo, clima, máquina e operador, esses com experiência e produtividades similares.

\section{Sistema de colheita florestal}

O sistema de colheita foi o de toras curtas, com o eito de derrubada composto por três linhas de árvores. O corte de derrubada era realizado com $o$ feller-buncher, que cortava e acumulava os fustes, formando feixes de árvores. A derrubada das árvores era direcionada para o lado oposto das árvores em pé e os feixes eram posicionados ao chão formando ângulo de aproximadamente $45^{\circ}$ em relação ao alinhamento de plantio.

A etapa seguinte foi o processamento da madeira, composto pelas atividades de desgalhamento, traçamento, destopamento e empilhamento dos toretes, realizado pelo processador florestal, que se deslocava no mesmo eito de derrubada do feller-buncher no sentido oposto, iniciando o processamento dos feixes de árvores pela extremidade do talhão.

\section{Descrição das máquinas}

O feller-buncher era constituído por uma máquina base com estrutura de escavadora hidráulica da marca Caterpillar modelo CAT $320 \mathrm{CL}$, equipado com motor diesel modelo 3066-T, com 103 kW de potência nominal, com 3.680 horas de uso acumulada e sistema de rodados de esteiras. A grua era modelo Scavator para alcance máximo de 8,83 metros, com massa operacional de $23.800 \mathrm{~kg}$ e equipado com um cabeçote de corte acumulador de disco, da marca Risley modelo H1818 TS.

A máquina base e a grua do processador florestal eram idênticas ao do feller-buncher, entretanto, estava com 2.460 horas de uso acumulada, com massa operacional de $22.960 \mathrm{~kg}$. $\mathrm{O}$ cabeçote processador era da marca $M S U$ modelo GF 1295 .

\section{Coleta dos dados}

A coleta dos dados de tempos e movimentos foi efetuada pelo método de cronometragem de tempo contínuo. Esse método caracteriza-se pela medição do tempo sem detenção do cronômetro, isto é, de forma contínua (SIMÕES et al., 2010). Os dados foram obtidos nos mesmos horários e condições climáticas, as quais se mantiveram sem alterações, com o céu encoberto e com períodos de sol durante o período do estudo. A operação de colheita florestal foi subdividida em atividades parciais e, estas classificadas em atividades efetivas e atividades gerais.

As atividades efetivas englobaram todos os movimentos planejados que ocorreram durante o decurso da operação os quais resultaram em produção ou foram necessários para a realização do trabalho. Para o feller-buncher essas atividades foram o deslocamento vazio e, a busca e corte das árvores e do processador florestal o deslocamento vazio e processamento dos feixes de árvores.

As atividades gerais foram as mesmas para o feller-buncher e para o processador florestal. As atividades gerais foram as que ocorreram casualmente durante o decurso do trabalho, mas não resultaram em produção, compreendidas pelas interrupções: interrupções operacionais decorrentes do tempo despendido para a manutenção preventiva ou corretiva das máquinas e as não operacionais, destinadas às necessidades fisiológicas dos operadores.

O número de ciclos operacionais foi estimado de acordo com a metodologia proposta por Barnes (1968). Por meio de um estudo-piloto foi estimado o número mínimo de ciclos operacionais para um erro de amostragem admissível fixado em $5 \%$, a $95 \%$ de probabilidade (Equação 1).

$$
n \geq \frac{t^{2} C V^{2}}{E^{2}}
$$

Em que: $\mathrm{n}$ - número mínimo de ciclos operacionais necessários; $\mathrm{t}$ - valor t de Student, no nível de probabilidade desejado e (n-1) graus de liberdade; CV - coeficiente de variação (\%);

E - erro admissível (\%).

\section{Análise técnica}

A produtividade foi estimada em metros cúbicos de madeira colhida ou processada, por hora efetiva de trabalho $\left(\mathrm{m}^{3}\right.$ he $\left.{ }^{-1}\right)$ (Equação 2).

$$
P=\frac{v}{T}
$$


Em que: $\mathrm{P}$ - produtividade $\left(\mathrm{m}^{3} \mathrm{he}^{-1}\right) ; \mathrm{v}-$ volume, em metros cúbicos de madeira $\left(\mathrm{m}^{3}\right) ; \mathrm{T}-$ tempo em horas efetiva (he).

O volume de madeira foi obtido multiplicando o número de árvores derrubadas ou de toretes processados pelo volume médio obtido por meio de inventário.

A disponibilidade mecânica foi definida como o percentual do tempo que a máquina estava apta a realizar o trabalho. Portanto, desconsiderouse o tempo em que a máquina estava em manutenção preventiva ou corretiva. De acordo com Oliveira et al. (2009), a eficiência operacional é a percentagem do tempo efetivamente trabalhado, em relação ao tempo programado para o trabalho, sendo determinada pela Equação 3 .

$$
E O=\frac{h e}{h e+h p} 100
$$

Em que: EO- eficiência operacional (\%); he - tempo efetivo de trabalho (horas); hp - tempo de horas paradas (horas).

\section{Análise econômica}

Os custos operacionais foram estimados de acordo com a metodologia proposta pela American Society of Agricultural Engineers (ASAE, 2001) e foram expressos em dólar comercial americano, oficial do Banco Central do Brasil (PTAX 800) a preço de venda, por hora de trabalho $\left(\mathrm{US} \$ \mathrm{~h}^{-1}\right)$. Foi considerado como taxa de câmbio o preço da moeda estrangeira medido em unidades e frações da moeda nacional, que era de $\mathrm{R} \$ 1,8032$ em 20/12/2007 (BANCO CENTRAL DO BRASIL, 2011).

Para estimar os custos operacionais foram considerados os custos fixos (depreciação, juros simples, abrigo, custo de administração e seguros) e variáveis (combustíveis, manutenção, lubrificantes e mão de obra). O custo operacional foi obtido pelo somatório dos custos fixos e variáveis e o custo de colheita e processamento da madeira (US\$ $\mathrm{m}-{ }^{3} \mathrm{cc}$ ) por meio da divisão dos custos operacionais pela produtividade. Para ambas as máquinas foi considerada uma taxa de juros de $10 \%$ a.a. e vida útil de 4 anos, com um valor residual de $48 \%$.

$\mathrm{O}$ rendimento energético, o qual indica a massa de combustível necessária para produzir uma unidade de potência na unidade de tempo (SIMÕES et al., 2010), foi obtido pela razão entre o consumo específico efetivo de combustível em gramas para cada kilowatt fornecido durante uma hora $\left(\mathrm{g} \mathrm{kW}^{-1} \mathrm{~h}^{-1}\right)$ e a produtividade média $\left(\mathrm{m}^{3} \mathrm{cc}\right.$ $\mathrm{he}^{-1}$ ) expressa em: $\mathrm{g} \mathrm{kW}^{-1} \mathrm{~m}^{3} \mathrm{cc}$. Para o cálculo do consumo específico efetivo (CSE) foi utilizada a metodologia proposta pela United Nations Economic Commission for Europe (UNECE, 2007), conforme a Equação 4.

$$
C S E=\frac{G_{f}}{P_{e}}
$$

Em que: CSE - Consumo específico efetivo $\left(\mathrm{g} \mathrm{kW}^{-1} \mathrm{~h}^{-1}\right)$; Gf - Consumo horário em carburante

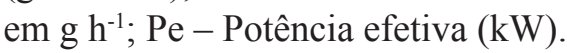

O rendimento energético foi obtido de acordo ao utilizado por Lopes (2007), em análise técnica e econômica de um sistema de colheita florestal.

$$
R E=\frac{C S E}{P}
$$

Em que: RE - rendimento energético da máquina avaliada $\left(\mathrm{g} \mathrm{kW}^{-1} \mathrm{~m}^{3} \mathrm{cc}\right)$; CSE - Consumo específico efetivo $\left(\mathrm{g} \mathrm{kW}^{-1} \mathrm{he}^{-1}\right) ; \mathrm{P}$ - produtividade $\left(\mathrm{m}^{3} \mathrm{cche} \mathrm{e}^{-1}\right)$.

\section{Delineamento estatístico}

Os resultados obtidos foram submetidos à técnica da análise de variância para experimentos inteiramente casualizados, com 3 repetições em cada parcela experimental. Realizou-se o teste de Tukey na comparação de médias, para observar se houve diferença significativa, a $5 \%$ de probabilidade de erro.

Foi avaliado se as produtividades das máquinas envolvidas no estudo apresentam associação com o custo de colheita, com o custo de processamento da madeira e rendimento energético. Para isso foi obtido o grau de associação efetuandose a análise da matriz de coeficiente da correlação (r) de Pearson, pelo teste t a 5 e $1 \%$ de probabilidade.

\section{RESULTADOS E DISCUSSÃO}

Foi estabelecido para um erro de amostragem admissível em 5\% o número mínimo de ciclos operacionais, sendo 246 para o fellerbuncher e 188 para o processador florestal. Durante o estudo foram observados, respectivamente, 853 e 474 ciclos operacionais, o que possibilita uma maior confiabilidade na análise. O tempo total da operação foi de 17,48 horas, permitindo a colheita 
de 4.674 árvores.

\section{Estudo de tempos e movimentos}

Os tempos das atividades parciais (Tabela 2) do feller-buncher corresponderam a um ciclo operacional médio de 4,5 árvores colhidas realizados em 37,52 segundos. Os resultados das análises mostram que houve diferença significativa pelo teste de Tukey, no nível de confiança de 95\% somente para a atividade parcial de deslocamento vazio. Essa diferença é explicada pelo menor número de árvores nas parcelas 3 e 5, decorrente de falhas no plantio (árvores mortas), o que pode comprometer o tempo da atividade parcial "buscar e cortar" em função dessas estarem correlacionadas. A atividade parcial que despendeu maior tempo do ciclo operacional foi "buscar e cortar" a qual representou em média $65,14 \%$, seguida pelo "deslocamento vazio" com $27,85 \%$. As interrupções operacionais (reparos e manutenção) representaram $4,23 \%$ e as não operacionais $2,78 \%$.

Em relação ao ciclo operacional do processador florestal, esse demandou um tempo médio de 55,90 segundos, possibilitando o processamento de 8,9 árvores, sendo obtido em média 2,9 toretes por árvore, com comprimento de 6 metros. Como pode ser observado na (Tabela 3), o tempo da atividade parcial "processar" foi estatisticamente diferente entre as parcelas. Esse fato pode estar associado ao arranjo dos feixes de árvores no chão, o que implicava em uma variação do tempo de acomodação das árvores na garra do processador florestal, que, consequentemente, originou uma diferença estatística a $5 \%$ de probabilidade para o tempo efetivo do ciclo operacional. O percentual

TABELA 2:Tempo médio do ciclo operacional do feller-buncher.

TABLE 2: Average time of the operational cycle of feller-buncher.

\begin{tabular}{ccccccc}
\hline \multirow{2}{*}{$\begin{array}{c}\text { Parcelas } \\
\text { experimentais }\end{array}$} & $\begin{array}{c}\text { Buscar e } \\
\text { cortar }\end{array}$ & $\begin{array}{c}\text { Deslocamento } \\
\text { vazio }\end{array}$ & Manutenção & $\begin{array}{c}\text { Tempo } \\
\text { pessoal }\end{array}$ & $\begin{array}{c}\text { Atividade } \\
\text { efetiva }\end{array}$ & Total \\
\hline 1 & $27,51 \mathrm{a}$ & $10,59 \mathrm{~b}$ & $0,68 \mathrm{a}$ & $0,64 \mathrm{a}$ & $38,09 \mathrm{a}$ & $39,42 \mathrm{a}$ \\
2 & $26,59 \mathrm{a}$ & $10,55 \mathrm{~b}$ & $0,57 \mathrm{a}$ & $0,91 \mathrm{a}$ & $37,15 \mathrm{a}$ & $38,62 \mathrm{a}$ \\
3 & $26,04 \mathrm{a}$ & $11,06 \mathrm{ab}$ & $0,66 \mathrm{a}$ & $0,13 \mathrm{a}$ & $37,11 \mathrm{a}$ & $37,89 \mathrm{a}$ \\
4 & $26,34 \mathrm{a}$ & $10,69 \mathrm{~b}$ & $0,65 \mathrm{a}$ & $0,13 \mathrm{a}$ & $37,03 \mathrm{a}$ & $37,81 \mathrm{a}$ \\
5 & $25,56 \mathrm{a}$ & $12,64 \mathrm{a}$ & $0,52 \mathrm{a}$ & $0,13 \mathrm{a}$ & $38,20 \mathrm{a}$ & $38,86 \mathrm{a}$ \\
\hline $\mathrm{CV}(\%)$ & 28,30 & 27,84 & 37,10 & 53,20 & 22,48 & 41,80
\end{tabular}

Em que: Médias seguidas de mesma letra na coluna não diferem, estatisticamente, entre si, pelo teste de Tukey, a 5\% de probabilidade.

TABELA 3: Tempo médio do ciclo operacional do processador florestal.

TABLE 3: Average time of the operational cycle of the forest processor.

\begin{tabular}{ccccccc}
\hline \multirow{2}{*}{$\begin{array}{c}\text { Parcelas } \\
\text { experimentais }\end{array}$} & Processar & $\begin{array}{c}\text { Deslocamento } \\
\text { vazio }\end{array}$ & Manutenção & $\begin{array}{c}\text { Tempo } \\
\text { pessoal }\end{array}$ & $\begin{array}{c}\text { Atividade } \\
\text { efetiva }\end{array}$ & Total \\
\hline 1 & $41,24 \mathrm{c}$ & $13,69 \mathrm{a}$ & $0,93 \mathrm{a}$ & $0,67 \mathrm{a}$ & $54,93 \mathrm{ab}$ & $56,53 \mathrm{a}$ \\
2 & $43,20 \mathrm{ab}$ & $12,75 \mathrm{a}$ & $0,88 \mathrm{a}$ & $0,85 \mathrm{a}$ & $55,94 \mathrm{ab}$ & $57,68 \mathrm{a}$ \\
3 & $43,90 \mathrm{ab}$ & $13,84 \mathrm{a}$ & $0,79 \mathrm{a}$ & $0,56 \mathrm{a}$ & $57,75 \mathrm{a}$ & $59,34 \mathrm{a}$ \\
4 & $45,58 \mathrm{a}$ & $12,56 \mathrm{a}$ & $0,82 \mathrm{a}$ & $0,74 \mathrm{a}$ & $58,13 \mathrm{a}$ & $59,70 \mathrm{a}$ \\
5 & $40,39 \mathrm{c}$ & $12,41 \mathrm{a}$ & $0,85 \mathrm{a}$ & $0,74 \mathrm{a}$ & $52,79 \mathrm{~b}$ & $54,38 \mathrm{a}$ \\
\hline CV $(\%)$ & 19,35 & 18,66 & 42,51 & 44,30 & 16,27 & 31,68 \\
\hline
\end{tabular}

Em que: Médias seguidas de mesma letra na coluna não diferem, estatisticamente, entre si, pelo teste de Tukey, a 5\% de probabilidade. 
médio da atividade parcial "processar" foi de $74,69 \%$ do tempo total, posteriormente vieram o "deslocamento vazio" com 22,13\%, as interrupções (operacionais e não operacionais) que, contíguas, representaram $3,18 \%$ do tempo total do ciclo operacional.

\section{Produtividade}

A produtividade média do feller-buncher por hora efetiva de trabalho não foi estatisticamente diferente a $5 \%$ de probabilidade. A quantidade de árvores abatidas foi de 499, 516, 545, 539 e 523 e em metros cúbicos com casca 109,53, 115,78, 127,50, 119,00 e 120,56 nas parcelas 1 a 5, respectivamente. Esses resultados mostraram-se superiores aos resultados dos estudos realizados por Fiedler et al. (2008), Fernandes et al. (2009) e Nascimento et al. (2011), os quais avaliaram máquinas com características semelhantes e em relevo plano, entretanto, esses autores não relatam se a colheita foi realizada em um povoamento de primeiro corte. Supõe-se que esses autores realizaram seus estudos em florestas com a presença de árvores provenientes de condução ou com bifurcação, pois o fellerbuncher é comumente utilizado em florestas que possuem essas condições, o que não ocorreu neste estudo.

No que se refere à produtividade média do processador florestal por hora efetiva de trabalho, essa também foi semelhante estatisticamente para todas as parcelas experimentais, pelo teste de Tukey, no nível de 5\% de probabilidade. Foram processadas 678, 609, 561, 613 e 598 árvores e em metros cúbicos com casca 148,68, 135,65, $131,10,135,80$ e 137,65 para as parcelas 1 a 5 , respectivamente. Tarnowski et al. (1999) estimaram a produtividade média teórica do processador florestal em um povoamento de Eucalyptus grandis Hill ex Maiden em 126 árvores por hora e $42,30 \mathrm{~m}^{3} \mathrm{cc}$ $\mathrm{h}^{-1}$. Essa diferença deve-se, principalmente, devido ao comprimento dos toretes, que é uma variável correlacionada à produtividade e ao tipo de floresta, pois esses autores avaliaram toretes de 2,8 metros e nesse estudo foram de 6 metros de comprimento. No entanto, Santos e Machado (1995) avaliaram um processador trabalhando em florestas de eucalipto, traçando as árvores em toretes de 6 metros de comprimento e obtiveram uma produtividade máxima de $28,50 \mathrm{~m}^{3} \mathrm{cc} \mathrm{h}^{-1}$. O contraste dessas produtividades pode ser decorrente da possibilidade de existirem árvores bifurcadas no estudo desses autores, o que não havia no povoamento avaliado.

Diversos autores relatam existir uma variação da produtividade das máquinas florestais por diversos fatores, dentre esses se destaca o volume médio individual das árvores. Akay et al. (2004), Silva et al. (2007) e Malinovski et al. (2006) analisaram esse efeito sobre a produtividade. Pode ser confirmada essa relação por meio da Figura 1, onde é apresentado o logaritmo decimal, ajustado para o modelo de potência, onde $\mathrm{Y}=$ representa a produtividade e $\mathrm{X}=\mathrm{o}$ volume individual. Observase que houve um aumento da produtividade do feller-buncher de forma linear em função do volume individual das árvores, explicando em,
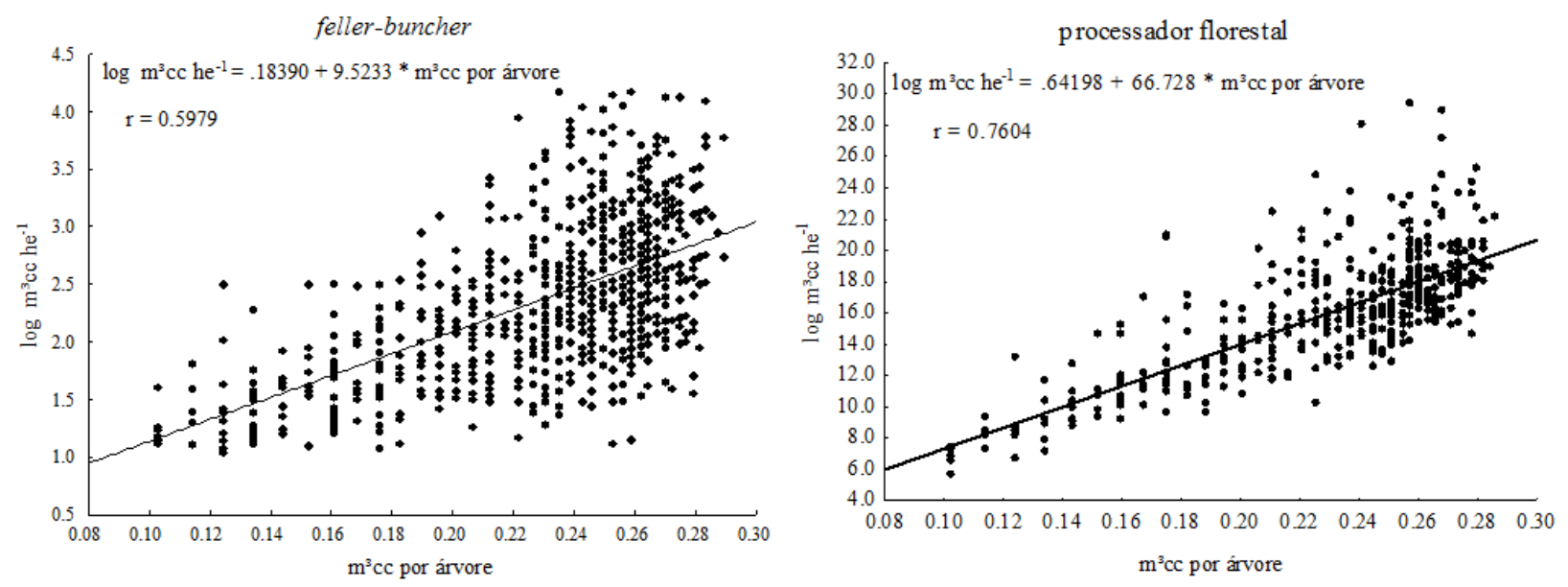

FIGURA 1: Gráfico do logaritmo da produtividade em relação ao volume individual das árvores. FIGURE 1: Graph of the logarithm of the productivity in relation to volume of individual trees. 
aproximadamente, $60 \%$ o resultado obtido. Já para o processador florestal essa relação ficou próxima a $76 \%$.

\section{Disponibilidade mecânica e eficiência operacional}

A disponibilidade mecânica média de ambas as máquinas foi de aproximadamente $97 \%$. Para o feller-buncher houve uma diferença significativa somente durante a avaliação na parcela experimental 4, em virtude de um maior tempo despendido para efetuar a substituição de mangueiras hidráulicas. Quanto ao processador florestal, a disponibilidade mecânica não diferiu estatisticamente entre as parcelas. A razão do elevado percentual de disponibilidade mecânica pode ser explicada pela baixa quantidade de horas de uso acumulado. Em relação à eficiência operacional, tanto para o feller-buncher quanto para o processador florestal, não houve diferença significativa nas parcelas experimentais, pelo teste de Tukey, no nível de 5\% de probabilidade (Tabela 4).

\section{Custo operacional}

Na Figura 2 é apresentado o gráfico em percentuais dos custos operacionais para ambas as máquinas. O somatório dos custos fixos e variáveis do feller-buncher resultou um custo operacional de US\$ 85.28 por hora de trabalho. Os custos fixos (depreciação, juros, abrigo, taxas e seguros) corresponderam a $30,37 \%$ e os custos variáveis (combustível, reparos e manutenção, lubrificação e mão de obra) representaram 69,63\%. Para o processador florestal, o custo operacional calculado foi de US\$ 72.87 , com $27,09 \%$ de participação dos custos fixos e $72,91 \%$ dos custos variáveis. De acordo com Machado (1989), existem muitas técnicas de estimativa de custo operacional, mas nenhuma delas é perfeita, resultando em diferenças ocasionadas pela política ou contabilidade da empresa. No entanto, é importante salientar que os percentuais dos custos fixos e variáveis obtidos foram próximos aos calculados por Nascimento et al. (2011), Fernandes et al. (2009) e Souza et al. (2004), aumentando dessa forma a confiabilidade desses resultados.

\section{Custo de colheita florestal e rendimento energético}

O custo médio de colheita florestal do feller-buncher foi de US\$ $0.72 \mathrm{~m}^{3} \mathrm{cc}$ e o custo de processamento da madeira realizada pelo processador florestal foi de US $\$ 0.54 \mathrm{~m}^{3} \mathrm{cc}$. Devido à necessidade das atividades de corte, desgalhamento, destopamento, traçamento e empilhamento dos toretes serem realizadas de forma conjugada pelo feller-buncher e processador florestal, o custo médio para esse sistema de colheita foi de US\$ $1.26 \mathrm{~m}^{3}$ cc. Fernandes et al. (2009), em avaliação de sistemas de colheita, pressupondo-se em florestas com árvores bifurcadas, obtiveram para o fellerbuncher e garra traçadora na melhor produtividade um custo total de US\$2.31. No entanto, Simões et al. (2010) verificaram que o custo de colheita com o harvester em floresta de primeiro corte e demais condições semelhantes desse estudo, obtiveram para a melhor produtividade um custo de US\$ $2.13 \mathrm{~m}^{3}$ cc. Sendo assim, o emprego do feller-buncher e do

TABELA 4:Disponibilidade mecânica e eficiência operacional média.

TABLE 4: Mechanical availability and mean operational efficiency.

\begin{tabular}{ccccc}
\hline \multirow{2}{*}{$\begin{array}{c}\text { Parcelas } \\
\text { experimentais }\end{array}$} & \multicolumn{2}{c}{ feller-buncher } & \multicolumn{2}{c}{ Processador florestal } \\
\cline { 2 - 5 } & $\begin{array}{c}\text { Disponibilidade } \\
\text { mecânica (\%) }\end{array}$ & $\begin{array}{c}\text { Eficiência } \\
\text { operacional (\%) }\end{array}$ & $\begin{array}{c}\text { Disponibilidade } \\
\text { mecânica (\%) }\end{array}$ & $\begin{array}{c}\text { Eficiência operacional } \\
(\%)\end{array}$ \\
\hline 1 & $100,00 \mathrm{a}$ & $95,51 \mathrm{a}$ & $100,00 \mathrm{a}$ & $100,00 \mathrm{a}$ \\
2 & $100,00 \mathrm{a}$ & $93,59 \mathrm{a}$ & $100,00 \mathrm{a}$ & $96,95 \mathrm{a}$ \\
3 & $100,00 \mathrm{a}$ & $86,29 \mathrm{a}$ & $91,58 \mathrm{a}$ & $91,57 \mathrm{a}$ \\
4 & $86,56 \mathrm{~b}$ & $98,84 \mathrm{a}$ & $100,00 \mathrm{a}$ & $100,00 \mathrm{a}$ \\
5 & $100,00 \mathrm{a}$ & $98,85 \mathrm{a}$ & $100,00 \mathrm{a}$ & $93,72 \mathrm{a}$ \\
\hline C.V. (\%) & 10,41 & 11,44 & 6,64 & 7,63 \\
\hline
\end{tabular}

Em que: Médias seguidas de mesma letra na coluna não diferem, estatisticamente, entre si, pelo teste de Tukey, a 5\% de probabilidade. 

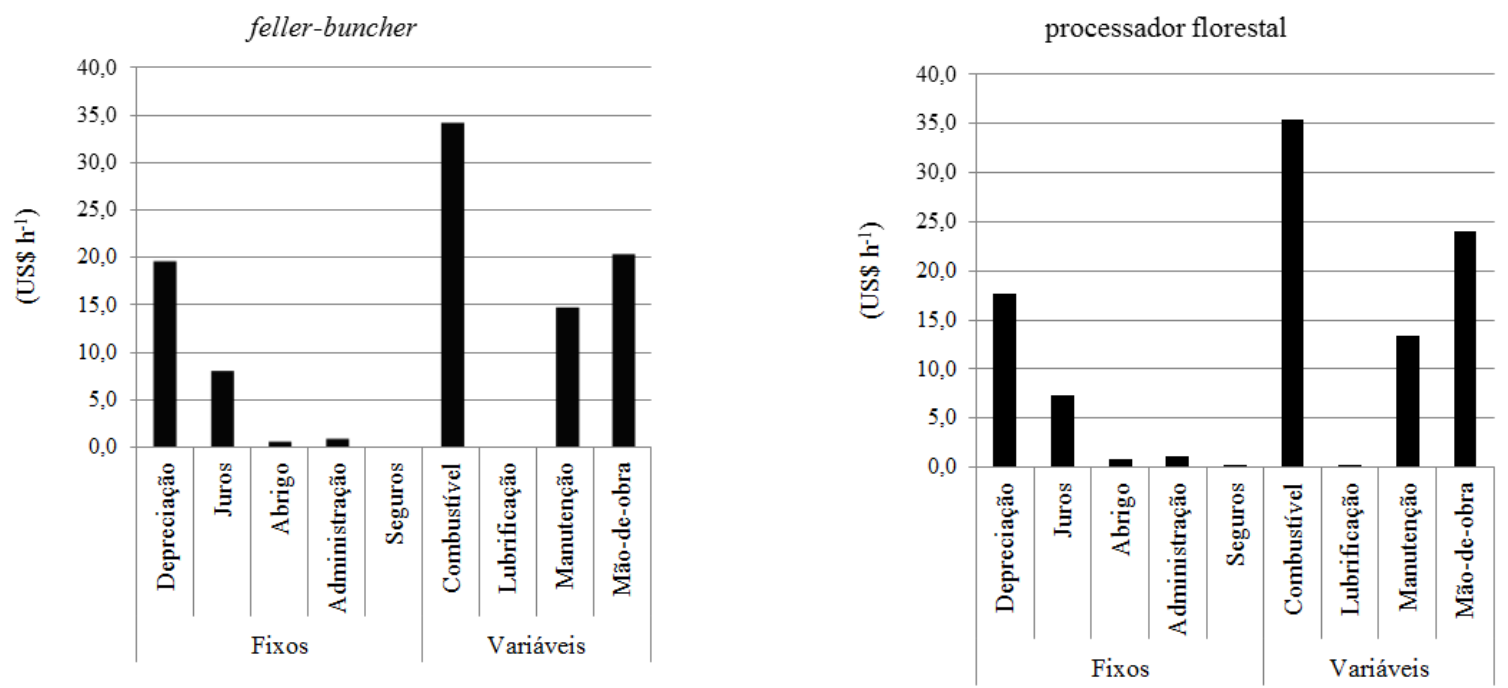

FIGURA 2: Distribuição percentual dos itens que compõem o custo operacional das máquinas avaliadas. FIGURE 2: Percent distribution of the items which compose the operational cost of the machines evaluated.

processador florestal em povoamentos florestais de primeiro corte é uma alternativa economicamente viável, pois comumente esse sistema é empregado em florestas que foram conduzidas ou que possuem árvores bifurcadas.

Em análise, o custo de colheita florestal do feller-buncher, observa-se na Tabela 5 que o custo na parcela experimental 3 diferiu estatisticamente ao nível de $5 \%$ das demais parcelas, fato esse explicado pela melhor produtividade obtida. O custo de processamento da madeira realizado pelo processador florestal não apresentou diferença estatística pelo teste de Tukey a 5\%.

Quanto ao rendimento energético, esse apresentou semelhança estatística para ambas as máquinas em todas as parcelas experimentais. $\mathrm{O}$ consumo horário do carburante utilizado pelo fellerbuncher foi de $26 \mathrm{lh}^{-1}$, resultando num consumo específico de combustível de 211,30 ( $\left.\mathrm{g} \mathrm{kW}^{-1} \mathrm{~h}^{-1}\right)$. Para o processador florestal, o consumo horário foi de $23 \mathrm{lh}^{-1}$, consequentemente promoveu um consumo específico de 186,68 $\left(\mathrm{g} \mathrm{kW}^{-1} \mathrm{~h}^{-1}\right)$.

Ao se observar as Tabelas 6 e 7 pode-se constatar o sinal do coeficiente de correlação (r) de

TABELA 5: Custos de colheita e processamento da madeira e, rendimento energético das máquinas avaliadas.

TABLE 5: Costs of harvesting and wood processing cost and, energy consumption rate of the machines evaluated.

\begin{tabular}{|c|c|c|c|c|}
\hline \multirow[b]{2}{*}{$\begin{array}{c}\text { Parcelas } \\
\text { experimentais }\end{array}$} & \multicolumn{2}{|c|}{ feller-buncher } & \multicolumn{2}{|c|}{ Processador florestal } \\
\hline & $\begin{array}{l}\text { Custo de colheita } \\
\text { florestal } \\
\left(\mathrm{US} \$ \mathrm{~m}^{3} \mathrm{cc} \mathrm{he} \mathrm{h}^{-1} \text { ) }\right.\end{array}$ & $\begin{array}{l}\text { Rendimento energético } \\
\qquad\left(\mathrm{g} \mathrm{kW}^{-1} \mathrm{~m}^{3} \mathrm{cc}\right)\end{array}$ & $\begin{array}{c}\text { Custo de } \\
\text { processamento } \\
\left(\mathrm{US} \$ \mathrm{~m}^{3} \mathrm{cc} \mathrm{he}^{-1}\right)\end{array}$ & $\begin{array}{l}\text { Rendimento } \\
\text { energético } \\
\left(\mathrm{g} \mathrm{kW}^{-1} \mathrm{~m}^{3} \mathrm{cc}\right)\end{array}$ \\
\hline 1 & $0.78 \mathrm{a}$ & $1,94 \mathrm{a}$ & $0.51 \mathrm{a}$ & $1,31 \mathrm{a}$ \\
\hline 2 & $0.73 \mathrm{a}$ & $1,83 \mathrm{a}$ & $0.54 \mathrm{a}$ & $1,39 \mathrm{a}$ \\
\hline 3 & $0.66 \mathrm{~b}$ & $1,66 \mathrm{a}$ & $0.56 \mathrm{a}$ & $1,44 \mathrm{a}$ \\
\hline 4 & $0.72 \mathrm{a}$ & $1,77 \mathrm{a}$ & $0.54 \mathrm{a}$ & $1,39 \mathrm{a}$ \\
\hline 5 & $0.71 \mathrm{a}$ & $1,75 \mathrm{a}$ & $0.53 \mathrm{a}$ & $1,36 \mathrm{a}$ \\
\hline C.V. $(\%)$ & 8,07 & 8,06 & 12,68 & 12,67 \\
\hline
\end{tabular}

Em que: Médias seguidas de mesma letra na coluna não diferem, estatisticamente, entre si, pelo teste de Tukey, a 5\% de probabilidade. 
TABELA 6: Matriz de coeficiente da correlação (r) de Pearson para o feller-buncher.

TABLE 6: Matrix of Pearson's correlation coefficient ( $\mathrm{r}$ ) for feller-buncher.

\begin{tabular}{|c|c|c|c|}
\hline Variáveis & 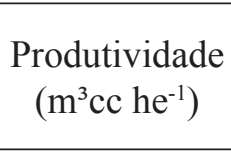 & $\begin{array}{c}\text { Custo de colheita } \\
\text { florestal } \\
\left(\mathrm{US} \$ \mathrm{~m}^{3} \mathrm{cche}^{-1}\right)\end{array}$ & $\begin{array}{c}\text { Rendimento } \\
\text { energético } \\
\left(\mathrm{g} \mathrm{kW}^{-1} \mathrm{~m}^{3} \mathrm{cc}\right)\end{array}$ \\
\hline Produtividade $\left(\mathrm{m}^{3} \mathrm{cc} \mathrm{he} \mathrm{h}^{-1}\right)$ & 1,00 & & \\
\hline Custo de colheita florestal (US\$ $\mathrm{m}^{3} \mathrm{cche}^{-1}$ ) & $-0,9942^{* *}$ & 1,00 & \\
\hline Rendimento energético $\left(\mathrm{g} \mathrm{kW}^{-1} \mathrm{~m}^{3} \mathrm{cc}\right)$ & $-0,9942^{* *}$ & $1,00^{* *}$ & 1,00 \\
\hline
\end{tabular}

Em que: ns - não significativo - * $\mathrm{e}^{* *}$ significativo a 5 e a $1 \%$ de probabilidade, respectivamente, pelo teste $\mathrm{t}$, com 14 graus de liberdade.

TABELA 7: Matriz de coeficiente da correlação (r) de Pearson para o processador florestal. TABLE7: Matrix of Pearson's correlation coefficient (r) for the forest processor.

\begin{tabular}{|c|c|c|c|}
\hline Variáveis & $\begin{array}{l}\text { Produtividade } \\
\left(\mathrm{m}^{3} \mathrm{cc} \mathrm{he}^{-1}\right)\end{array}$ & $\begin{array}{c}\text { Custo de } \\
\text { processamento } \\
\left(\mathrm{US} \$ \mathrm{~m}^{3} \mathrm{cc} \mathrm{he}^{-1}\right)\end{array}$ & $\begin{array}{c}\text { Rendimento } \\
\text { energético } \\
\left(\mathrm{g} \mathrm{kW}^{-1} \mathrm{~m}^{3} \mathrm{cc}\right)\end{array}$ \\
\hline Produtividade $\left(\mathrm{m}^{3} \mathrm{cc} \mathrm{he} \mathrm{e}^{-1}\right)$ & 1,00 & & \\
\hline Custo de colheita florestal (US\$ $\mathrm{m}^{3} \mathrm{cc} \mathrm{he}^{-1}$ ) & $-0,9875^{* *}$ & 1,00 & \\
\hline Rendimento energético $\left(\mathrm{g} \mathrm{kW}^{-1} \mathrm{~m}^{3} \mathrm{cc}\right)$ & $-0,9875^{* *}$ & $1,00^{* *}$ & 1,00 \\
\hline
\end{tabular}

Em que: ns - não significativo - * $\mathrm{e}^{* *}$ significativo a 5 e a $1 \%$ de probabilidade, respectivamente, pelo teste $\mathrm{t}$, com 14 graus de liberdade.

Pearson com as variáveis: produtividade, custo de colheita florestal, custo do processamento da madeira e rendimento energético. Para todas as variáveis houve uma correlação negativa com a produtividade $(\mathrm{P}<0,01)$, evidenciando a diminuição do custo da colheita florestal, custo do processamento da madeira e do rendimento energético com o aumento da produtividade.

\section{CONCLUSÕES}

O volume médio individual das árvores representa, em aproximadamente $60 \%$, a produtividade do feller-buncher, e em 76\%, a produtividade do processador florestal em florestas de eucalipto em primeiro corte, onde não há presença de árvores bifurcadas.

A produtividade média do feller-buncher foi de 524 árvores e em metros cúbicos 118,47 por hora efetiva de trabalho e, para o processador florestal, obteve-se uma produtividade média de 611 árvores e metros cúbicos 137,68 de madeira processada com casca, correspondendo a um custo médio de colheita florestal para esse sistema de US\$ $1.26 \mathrm{~m}^{3} \mathrm{cc} \mathrm{he} \mathrm{h}^{-1}$.

Com a operação do feller-buncher e processador florestal em povoamentos florestais que não foram conduzidos ou que não possuam árvores bifurcadas, é possível obter uma redução significativa nos custos de colheita florestal, sendo assim uma alternativa técnica e econômica viável para essas condições.

\section{REFERÊNCIAS BIBLIOGRÁFICAS}

AKAY, A. E. et al. Determining productivity of mechanized harvesting machines. Journal of Applied Sciences, Pakistan, v. 4, n. 1, p. 100-105, 2004.

AMERICAN SOCIETY OF AGRICULTURAL ENGINEERS.ASAE standards 2001: machinery, equipment, and buildings: operating costs. Ames, Iowa, USA, 2001. p. 164-226. (ASAE D472-3).

BANCO CENTRAL DO BRASIL. Conversão de moedas. Disponível em: < (http://www4.bcb.gov. br/?TXCONVERSAO)>. Acesso em: 02 de maio de 2011.

BARNES, R. M. Motion and time study: design and measurement ok work. 6th ed. New York: John Willey e Sons, 1968. 799 p.

CUNHA, A. R. et al. Classificação climática para o município de Botucatu, SP, segundo Köppen. In: SIMPÓSIO EM ENERGIA NA AGRICULTURA, 
1., 1999, Botucatu. Anais... Botucatu: SINERGIA, 1999. v. 2, p. 487-489.

FERNANDES, H. C. et al. Avaliação das características técnica e econômica de um sistema de colheita florestal de árvores inteiras. Scientia Forestalis, Piracicaba, v. 37, n. 83, p. 225-232, 2009.

FIEDLER, N. C. et al. Análise da produtividade de um sistema de colheita de árvores inteiras no norte do estado de Goiás. Floresta, Curitiba, v. 38, n. 4, p. 577-586, 2008.

LOPES, S. E. Análise técnica e econômica de um sistema de colheita florestal. 2007. 124 p. Tese (Doutorado em Engenharia Agrícola) - Universidade Federal de Viçosa, Viçosa, 2007.

LOPES, S. E. Avaliação técnica e econômica de uma garra traçadora operando em diferentes produtividades. Scientia Forestalis, Piracicaba, v. 36, n. 79, p. 215-222, 2008.

MACHADO, C. C. Sistema brasileiro de classificação de estradas florestais (SIBRACEF): desenvolvimento e relação com o meio de transporte florestal rodoviário. 1989. 188 f. Tese (Doutorado em Ciências Florestais) - Universidade Federal do Paraná, Curitiba, 1989.

MALINOVSKI, R. A.; MALINOVSKI, J. R. Evolução dos sistemas de colheita de madeira para pinus na região Sul do Brasil. Curitiba: FUPEF, 1998.108 p.

MALINOVSKI, R. A. et al. Análise das variáveis de influência na produtividade das máquinas de colheita de madeira em função das características físicas do terreno, do povoamento e do planejamento operacional florestal. Floresta, Curitiba, v. 36, n. 2, p. 169-182, 2006.

NASCIMENTO, A. C. Avaliação técnica e econômica da colheita florestal com feller-buncher. Cerne, Lavras, v. 17, n. 1, p. 9-15, 2011.

OLIVEIRA, D. et al. Avaliação técnica e econômica do Forwarder em extração de toras de pinus. Scientia Forestalis, Piracicaba, v. 37, n. 84, p. 525-533, 2009.

SANTOS, S. L. M.; MACHADO, C. C. Análise técnico-econômica do processamento de madeira em áreas planas, utilizando o processador. Revista Árvore, Viçosa, v. 19, n. 3, p. 346-357, 1995.

SILVA, J. R. et al. Avaliação do desempenho operacional de trator florestal "Feller-Buncher". Revista de Ciências Agroveterinárias, Lages, v. 6, n. 1, p. 29-34, 2007.

SIMÕES, D. et al. Avaliação técnica e econômica da colheita de florestas de eucalipto com harvester. Scientia Forestalis, Piracicaba, v. 38, n. 88, p. 611-618, 2010.

SIMÕES, D. et al. Avaliação técnica e econômica do corte de eucalipto com feller-buncher em diferentes condições operacionais. Ciência Florestal, Santa Maria, v. 20, n. 4, p. 649-656, 2010.

SOUZA, A. P. et al. Análise do desempenho da máquina "slingshot" em subsistemas de colheita em florestas de eucalipto. Revista Brasileira de Engenharia Agrícola e Ambiental, Campina Grande, v. 8, n. 2, p. 316-320, 2004.

TARNOWSKI, B. C. et al. Produtividade e custos do processador trabalhando em povoamento de Eucalyptus grandis Hill exMaiden. Ciência Florestal, Santa Maria, v. 9, n. 2, p. 103-115, 1999. UNITED NATIONS ECONOMIC COMMISSION FOR EUROPE. 63 $^{\text {rd }}$ session. Fuel consumption for vehicle powered refrigeration units based on a conception of standard vehicle engine. INF.3, Geneva, Switzerland, 2007.

VALVERDE, S. R. et al. Análise técnico-econômica do corte de madeira com o trator florestal derrubadoramontoador (feller-buncher) no sistema de colheita florestal de árvores inteiras de eucalipto. Revista Árvore, Viçosa, v. 20, n. 2, p. 229-40, 1996. 